\title{
DIZEM AS PAREDES: A ESCOLA PÚBLICA COMO ESPAÇO DE DISPUTA E NEGOCIAÇÃO DE VOZES E SILÊNCIOS
}

\section{SAY THE WALLS: THE PUBLIC SCHOOL AS A SPACE OF DISPUTE AND NEGOTIATION OF VOICES AND SILENCES}

DOI: http://dx.doi.org/10.5965/1984317816012020448

\author{
Marilia Alves de Carvalho \\ Universidade Estadual Paulista Júlio de Mesquita Filho \\ marilia.mac@gmail.com
}

\begin{abstract}
RESUMO
Este estudo consiste em um relato da experiência como professora de artes na rede municipal da cidade de São Paulo e das proposições de intervenções artísticas realizadas com estudantes do ensino fundamental II, como forma de ocupar o espaço da escola com as vozes das e dos estudantes e observar as repercussões e desdobramentos dessas ações. Partindo do aporte teórico da Cultura Visual para investigar sobre as imagens e a visualidade do ambiente escolar como atuantes na formação da subjetividade das e dos estudantes, assim como seu cotidiano e a forma como as relações se estabelecem dentro desse espaço, também é intenção desse artigo debater o entendimento das imagens que ocupam a escola como escolhas pedagógicas que dão visibilidade para determinados artefatos visuais ao mesmo tempo em que invisibilizam outros, assim como a relevância que elas podem ter na formação da voz e do silêncio das e dos estudantes. As considerações finais pretendem apontar possibilidades de entendimento das práticas artísticas e imagéticas como espaço de aprendizagem e experimentação que deve ser reconhecida e valorizada no cotidiano escolar.
\end{abstract}

Palavras-chave: Escola pública. Cultura Visual. Intervenção artística. Silenciamento.

\begin{abstract}
This study consists of an account of the experience as an art teacher in the municipal network of São Paulo city and the artistic intervention proposals carried out with students from 5th to 9th grade, as a way to occupy the school with the students' voices and observe the repercussions and consequences of these actions. Starting from the theoretical contribution of Visual Culture to investigate the images and visuality of the school environment as actors in the formation of students' subjectivity, as well as their daily life and the way relationships are established in school, it is also the intention of this article to discuss the understanding of the images that occupy the school as pedagogical choices that give visibility to certain visual artifacts while at the same time invisibilizing others, as well as the relevance that they can have in the formation of the students' voice and silence. The final considerations intend to point out possibilities for understanding artistic and imagery practices as a learning and experimentation space that should be recognized and valued in school everyday.
\end{abstract}

Keywords: Public school. Visual Culture. Artistic intervention. Silencing.

\section{INTRODUÇÃO}

Por que mostrar um dedo do meio (ou dar o dedo, como dizem alguns estudantes) é considerado um gesto ofensivo? Uma imagem de um dedo do meio 
fixada em uma parede pode ser tão ofensiva quanto o próprio gesto? Essa imagem seria mais ofensiva se estivesse fixada na parede de uma escola do que na rua? Há algum tipo de discurso ou mensagem que poderia justificar o uso de tal imagem dentro ou fora da escola? E se essa imagem estiver associada a uma mensagem de repúdio a algum tipo de opressão sofrida por algum grupo de pessoas dentro e fora desse espaço? Faria diferença se esse gesto fosse feito por uma mulher ou por um homem? E se fosse feito por uma adolescente?

Essas perguntas, que não pretendem necessariamente ser respondidas, são o ponto de partida para as reflexões que surgiram durante o processo de trabalho que venho desenvolvendo como professora de Artes em uma escola da Prefeitura Municipal de São Paulo, localizada na periferia da zona norte da cidade.

O ambiente escolar dessa onde leciono se assemelha ao de muitas outras escolas públicas da cidade, por operar dentro da lógica da proibição e da restrição: grades dentro e fora das salas de aula, paredes monocromáticas e lisas, quase nenhuma área aberta e muros altos que, de dentro, nos restringem a vista do céu, do dia e do tempo. As filas, o sinal fabril, o banho de sol na hora do intervalo, mais grades que fecham o acesso ao pátio. Além dos aspectos frios e hostis da arquitetura, podemos observar uma diversidade grande de informações visuais. É sobre a natureza dessas informações visuais e imagens, em paralelo a uma breve contextualização sobre os estudos da cultura visual, que se trata a primeira parte do artigo, seguida de um relato sobre uma das propostas de intervenção artística realizada com estudantes do $9^{\circ}$ ano e sua repercussão no ambiente escolar; por último, as considerações finais são uma reflexão sobre as relações de gênero e a formação de subjetividades a partir das estudantes no contexto da escola pública.

Por fim, cabe explicitar que "dizem as paredes" faz menção a pequenos contos de mesmo nome do autor uruguaio Eduardo Galeano (2002), em que ele descreve frases que encontra em pixações por diversas cidades, evidenciando a subjetividade e pensamentos de sujeitos constantemente apagados e invisibilizados pela cidade. Como, segundo o autor, disseram algumas paredes em Quito: "E se nos juntarmos para dar um chute nesta grande bolha cinzenta?". 


\section{A CULTURA VISUAL E VISUALIDADE NO AMBIENTE ESCOLAR}

Em 1981, Paulo Freire escreve que "a leitura do mundo precede sempre a leitura da palavra e a leitura desta implica continuidade da leitura daquele" (FREIRE, 1989, p. 13). Sob essa perspectiva, o autor entende que ler compreende um processo que não se limita a juntar sílabas, formar palavras e decodificá-las, mas que envolve uma percepção crítica, interpretação e reescrita do lido.

Ainda na década de 1980, caminhando em um sentido análogo ao que Paulo Freire propõe, Ana Mae Barbosa também busca ampliar a noção de leitura, destacando a leitura de imagens como um braço importante para o ensino da arte na pósmodernidade, considerando que:

Em nossa vida diária, estamos rodeados por imagens impostas pela mídia, vendendo produtos, ideias, conceitos, comportamentos, slogans políticos etc. Como resultado de nossa incapacidade de ler essas imagens, nós aprendemos por meio delas inconscientemente. A educação deveria prestar atenção ao discurso visual. Ensinar a gramática visual e sua sintaxe através da arte e tornar as crianças conscientes da produção humana de alta qualidade são uma forma de prepará-las para compreender e avaliar todo tipo de imagem, conscientizando-as de que estão aprendendo com estas imagens. (BARBOSA, 1998, p. 17).

Os dois autores sublinham a relação, nas palavras de Paulo Freire, do "texto com o contexto"; assim, inserem o ato de ler em uma perspectiva crítica e ao mesmo tempo criadora, uma vez que exige uma relação ativa daquele e daquela que lê com o que é lido, em que está implicado o lugar de onde se vê e as apropriações e ressignificações que cada sujeito é capaz de fazer a partir do seu lugar, que nunca é fixo.

A relevância da imagem para o ensino e aprendizagem das artes visuais e para uma leitura crítica do mundo adquire nova complexidade ao se voltar para a visualidade como forma de pensar sobre a relação que os indivíduos estabelecem com as imagens e os sentidos que são produzidos através dessas relações, o que implica também olhar para a normatização de determinados discursos e a consequente invisibilidade de outros. 
Nesse sentido, trago algumas contribuições dos estudos sobre a cultura visual em diálogo com o ensino das artes visuais como ponto para reflexão sobre o caráter discursivo mediado pelas imagens presentes no ambiente escolar, os efeitos que elas têm sobre os sujeitos que se relacionam com elas cotidianamente e na construção das subjetividades presentes nesse ambiente.

Ao buscar definições para cultura visual, Hernández (2005, p. 12) aponta uma grande diversidade de significados e perspectivas teórico-metodológicas, oriundas da confluência de diferentes disciplinas, tais como a Sociologia, a Semiótica, os Estudos Culturais e Feministas e a História Cultural da Arte. Dessa confluência temos, então, um campo de estudos que não se limita a debruçar-se sobre as produções artísticas e artefatos visuais constitutivos do espectro definido pelas instituições de arte como museus, galerias e a academia, mas se concentra sobretudo no complexo aparato de imagens e fenômenos visuais pelos quais somos cercados nos dias de hoje, tanto quanto nas práticas de visualidade que, segundo Hernández (2005, p.13), referem-se às "formas culturais vinculadas ao olhar", isto é, as formas como quem vê se posiciona diante do que é visto e como, simultaneamente, o visto constrói o olhar e o posicionamento discursivo de quem vê.

Retomando o cenário de onde parti, penso em um ambiente escolar cujas paredes estão repletas de folhas sulfites a4 com diversas cópias dos mesmos desenhos, cartolinas com aqueles conhecidos padrões de cores e os efeitos visuais do giz de cera pálido que não se destaca em nenhum tipo de papel e das marcas que a fita adesiva deixa depois de ser arrancada. Essa descrição, aliada a já mencionada frieza e hostilidade arquitetônica, refere-se à escola em que atuo e, ao mesmo tempo, deve ser familiar para muitas pessoas que jamais estiveram nela, pois também diz respeito a muitas outras escolas espalhadas pela cidade que igualmente insistem na manutenção dessas visualidades no imaginário escolar como a única possível. De dentro desse cenário encontramos aporte nas palavras de Irene Tourinho que nos leva a questionar sobre (2011, p. 12) os impactos que a experiência social do ver e ser visto, assim como os usos dessas experiências e visualidades tem sobre nossos "modos de ver, modos de ser, de agir, de desejar e de imaginar". Considerando a multiplicidade de sentidos, significados e usos que compreendem essas experiências (de ver e ser visto), a autora aponta a 
responsabilidade que a escola deveria ter no sentido de lidar com as diversidades e vulnerabilidades dessas experiências, entendendo-as como constituintes de nossas subjetividades, afetividades e identidades.

Segundo Tourinho (2011, p. 10), a ideia de "ser visto" não sugere necessariamente ver a própria imagem, mas indica ser visto culturalmente através dos significados atribuídos e mediados por outras imagens. Para Hernández (2005, p. 12), esse papel de mediar significações culturais exercido pelos artefatos visuais seria uma via de aproximação entre a cultura visual e o ensino das artes visuais. Cabe a nós então observar, nesse contexto escolar, em que medida as estudantes se veem e são vistas, quais espaços tem para representarem a si mesmas em contraponto às inúmeras imagens prontas e estereotipadas reproduzidas pela visualidade escolar e, ainda, se elas se veem e se reconhecem diante dessas imagens ou se tem espaços para reinventar seus modos de ver, de ser, de agir, de desejar, de imaginar e de serem vistas.

Com exceção de algumas poucas pinturas antigas em paredes do pátio da escola e das pixações que, via de regra, não são autorizadas, a maior parte das informações visuais presentes na escola não foi produzida por estudantes. Os trabalhos e atividades expostos, ainda que realizado por estudantes, são propostos e organizados pelo corpo docente assim como as decorações da chegada da primavera, de um dia do índio estereotipado e enfeites "fofos" com personagens da Turma da Mônica ou dos Minions dentro das salas de aula, são imagens predominantes e não encontram nenhuma resistência entre a comunidade escolar.

As referências visuais nesse ambiente escolar são, em sua maioria redundantes e repetitivas, pouco diversas e, nas palavras de Tourinho (2009, p. 152) "mantém um discurso infantilizado, adocicado, terapêutico ou, às vezes, puramente recreativo", além de limitarem-se a padrões estéticos predeterminados pelas cores e qualidade de materiais disponíveis que caracterizam e contaminam o imaginário escolar. Cores de cartolina, papel a4: o formato está dado, já vem pronto. A fôrma, o sapato em que apertamos os pés para caber todos os dedos. Apertar para caber.

As limitações materiais e físicas condicionadas pela precarização e sucateamento do ensino público determinam o tipo de experiências visuais possíveis 
dentro desse espaço? Apesar de faltar tanto, não teremos escolha além da manutenção da normatização visual porque "é o que temos pra hoje"? Ou qual seria o preço da escolha por outros caminhos que tentem reformular esses modos de ver, ser, agir, desejar e imaginar nesse espaço apesar de tudo o que falta nele? Como afirma Tourinho:

Os discursos visuais fazem concessões aos gostos, aos ideais, aos mercados, aos contextos onde precisam ou querem sobreviver. $\mathrm{O}$ discurso visual que a escola tem visto, imaginado, legitimado e reforçado, agride pelo excesso de concessões. Excesso como redundância. Falta formação, falta material, falta espaço, falta tempo, mas, falta também "molecar" com os artefatos que nos rodeiam. Fazer deles e com eles, objetos de nossas licenciosidades discursivas e metodológicas. (2009, p. 146)

Essa ambivalência entre o excesso (de concessões e redundâncias) e a falta sobretudo de "molecar", termo que a autora empresta do poeta Manoel de Barros, evidencia a preponderância de um discurso visual de fácil apreensão, impregnado de uma lógica voltada para o consumo e, por isso, palatável, convincente e que não propõe nenhum desafio nem exige muito de quem olha, não nos deixa "molecar" com camadas mais profundas de leitura e interpretação, tampouco com de criar e se reinventar a partir delas.

Considerando necessária a compreensão do contexto de produção e recepção das imagens, como nos recorda Kevin Tavin (2009, p.227), podemos perceber que uma característica comum entre essas imagens já mencionadas é estarem inseridas em uma lógica mercadológica de produção e distribuição, sendo portanto mais fácil e amplamente difundidas, aceitas e incorporadas ao gosto e repertório visual das crianças e adolescentes. A escola, esse lugar em que falta e sobra tanta coisa, recebe essas imagens de forma massiva e com tanta naturalidade que elas tomam forma de norma e, uma vez normatizadas, passam isentas de questionamentos sobre seu posicionamento político e ideológico e quais efeitos exercem sobre as pessoas que lidam e convivem com elas cotidianamente em um espaço sabidamente pedagógico.

Então temos uma coruja na porta da sala de leitura. E outras várias corujas decorando o interior dessa sala. Peço licença aqui para algumas digressões em 
primeira pessoa sobre essa coruja que todo dia me olha. Olho todo dia para a coruja de volta e me pergunto o que a levou ali. Uma coruja fofa, feita de E.V.A, genérica, que não se refere a nenhuma coruja específica que eu tenha conhecimento. Investigo mentalmente quais seriam as motivações que aquela coruja carrega, como objeto de decoração da sala de leitura: a relação imediata que faço é com a sabedoria, razão pela qual esse animal é usado como símbolo de áreas como a filosofia e a pedagogia. Essa associação parece coerente e talvez até um pouco óbvia, ao se tratar de um espaço da escola onde estão concentrados os livros, mas me lembro de alguém que me disse uma vez que o óbvio não existe. Então me pergunto: será óbvio para todas as pessoas que olham todo dia para aquela coruja algum significado relacionado à sabedoria? Se essa relação não for óbvia, quais outras relações são possíveis? Ou a coruja pode ser uma mera imagem decorativa, sem nenhuma significação e sem nenhum sentido - a priori ou atribuído por nós que tenha a ver com nosso dia a dia?

Essa associação aparentemente "óbvia" não vem apenas da visão e audição apuradas que a coruja tem, mas que, por ser uma ave noturna e porque os gregos valorizavam a noite como momento propício para o pensamento filosófico, a coruja simbolizava Athena, a deusa da sabedoria. Pesquisando na internet, apesar da incerteza das fontes, podemos ter uma dimensão de significados possíveis para a coruja: para os chineses, a sabedoria era representada pela sabedoria e a coruja representava o relâmpago e protegia dos raios. Já os aborígenes na Austrália acreditavam que a coruja representava o espírito da mulher, enquanto no xamanismo ela significaria transmutação e morte, na umbanda, justiça e no Candomblé, fertilidade. Mas tendo a acreditar que nenhum desses significados se aplicaria à nossa corujinha na porta da sala de leitura.

Com isso quero dizer que, nossas escolhas, ainda que inconscientes ou despretensiosas, carregam o peso histórico das narrativas dominantes (ocidentais, eurocêntricas, brancas, masculinas e heterossexuais) que são privilegiadas quando, por exemplo, não assumimos como pedagógicas as escolhas das imagens que circularão no ambiente escolar ou toda vez que nos eximimos da responsabilidade que temos em relação a essas escolhas e quando deixamos de discutir sobre elas. A questão não está centrada apenas na necessidade de olharmos para os significados 
culturais mediados por essas imagens, mas também em entendê-las como escolhas pedagógicas e atentarmos para o fato de que, ao escolhermos determinadas imagens e artefatos visuais simultaneamente escolhemos também aquilo que não será visto, que permanecerá à sombra ou mesmo invisível.

Não significa realizar uma caça às corujas, ursinhos, personagens de desenhos e qualquer outro tipo de imagens comuns ao imaginário escolar, nem de responsabilizar individualmente professoras e professores, mas como sugere Tourinho, nos perguntarmos "que culturas de atividade e práticas de responsabilização seriam necessárias e possíveis para que a escola lide com as experiências do ver e ser visto?" (2011, p. 13). Para a autora, algumas respostas para essa pergunta passariam por compreender a diversidade de abordagens possíveis para a cultura visual, reconhecer que hoje há muitos espaços de aprendizagem além da escola e que é possível borrar os limites definidos entre alunos e professores, cabendo a estes o exercício de

reconstruir, revisitar nossa formação identitária como profissionais, professores, implicados em (re)posicionamentos críticos sobre o mundo simbólico que nos rodeia, visa nos levar a despegar-nos de convicções rígidas, predispondo-nos a negociar identidades e a nos transformarmos. (TOURINHO, 2011, p. 14)

Em consonância a essa ideia, Hernández (2009, p. 206) também sugere repensar o papel da escola, "não para adaptá-la às necessidades do mercado, mas para dotar estudantes e professores de capacidades de ação e decisão na criação de suas próprias respostas frente aos processos de reestruturação nas sociedades pós-industriais". Essas práticas de responsabilização poderiam nos colocar, professoras/es, alunas/os e também gestão escolar, no lugar de sujeitos capazes de compreender a importância de nossas escolhas pedagógicas e de decidir e agir sobre elas de maneira consciente, criando espaços para contestar aquelas narrativas dominantes e não apenas conviver com elas como se fossem naturais e, portanto, isentas de questionamentos por serem entendidas a partir de uma suposta neutralidade nunca problematizada, nem entendida como formativa.

Acabou o semestre e as paredes voltam a ficar vazias e lisas, como o cubo branco de um museu sem exposições. É a estaca zero, o neutro, nulo. Prontas para 
começar de novo, aguardando a curadoria de quem pode decidir o que é digno de ser exposto, visto, exibido. E o que dizem essas paredes agora? Como é voltar das férias e mais uma vez elas terem nada para dizer? O "nada" nos conta quais são as "condições normais de temperatura e pressão" sob as quais a escola deve operar, como ela é, fixa e crua, antes de ser. O silêncio é uma norma que deve ser provisoriamente rompida com o que se espera que se diga: não sobre ele mesmo (o silêncio), nem sobre qualquer coisa que se gostaria de dizer. Há um script a ser seguido, há um acordo tácito sobre o que pode ser dito e não dito. Provisoriamente, até dezembro, quando tudo volta ao ponto inicial.

O silêncio é um aprendizado que perpassa várias camadas da vida escolar e, a longo prazo, corrói alguns mecanismos de criação e (re)invenção de si mesmo e do mundo e molda modos de ser e estar nesse mundo, principalmente quando o ambiente em que passamos a maior parte da nossa infância e adolescência não é instigador nem desafiador, pelo contrário, reduz e subestima aqueles e aquelas que convivem nele, além de apagar as marcas de vida, de uso, de gasto, de revolta, de amor e de história que se acumula nele ao longo dos meses.

\section{F*\#@-\$\& SEU MACHISMO: INTERVENÇÕES ARTÍSTICAS E OS SILÊNCIOS NA ESCOLA}

Durante o ano letivo de 2018 , foquei meu trabalho com as turmas dos $7^{\circ} \mathrm{s}, 8^{\circ} \mathrm{s}$ e $9^{\circ} \mathrm{s}$ anos do Ensino Fundamental II em intervenções artísticas, atentando para as percepções que as/os estudantes têm da escola e as possibilidades de ressignificar esse espaço repleto de normas e imagens já naturalizadas não apenas pela rotina escolar, mas também por ela.

Minha primeira proposta foi trabalhar com os $9^{\circ} \mathrm{S}$ a ideia de comunicação visual através de cartazes, com temas de livre escolha das/dos estudantes. A única restrição que estabeleci foi a de não ofender nenhum grupo de pessoas, nem qualquer pessoa individualmente (não valia querer "matar todos os palmeirenses", ou chamar o colega da outra sala de "viadinho", como alguns quiseram fazer).

Foram diversos fatores que me motivaram a escolher trabalhar com cartazes: o primeiro deles foi o entendimento desse tipo de produção como uma forma de 
divulgar ideias em locais públicos, o que exige uma atenção quanto à legibilidade e entendimento do queremos dizer, isto é, nos fazermos entender de maneira visual e estarmos sujeitos a olhares e leituras diversas, por se tratar de um espaço coletivo. Em segundo lugar, saber quais ideias habitava as cabeças das e dos estudantes, o que têm a dizer, o que achariam relevante colocar nas paredes da escola e como resolveriam essas ideias de forma visual. Por fim, minha pesquisa pessoal sobre letras e palavras enquanto imagens e a vontade de explorar e dividir isso em um processo criativo com as e os estudantes, sabendo que pra elas e eles, depois de (pelo menos) nove anos aprendendo a escrever e andar dentro da linha - uma linha reta - os desvios podem ser um obstáculo ou entendido como alvo de desconfiança: escrever em letras grandes, letras de forma, letras tortas, sem régua, contrastantes ou discretas, letras para serem lidas de longe, por várias pessoas, e não só por uma que dará um visto e o ponto na média do bimestre.

Percebi que durante esse processo, interrompido por uma greve de vinte dias de professoras/es e servidoras/es municipais da qual participei, a liberdade de escolha dos/das estudantes com relação aos temas que seriam trabalhados em seus cartazes não esteve dissociada dos cartazes que levei como referência (fig. 1 e 2) para serem analisados tanto pelas mensagens visuais e textuais, como pela relação entre elas e também pelos aspectos formais. O objetivo, entretanto, não era dissecar esses cartazes formalmente, mas sensibilizar o olhar das e dos estudantes para o processo de construção, leitura e veiculação dessas imagens. 


\section{EDUCAÇĀ̃O, ARTES $E$ INCLUSÃO}

Figura 1 cartazes levados como referências para leitura e análise durante a aula. (março/2018)

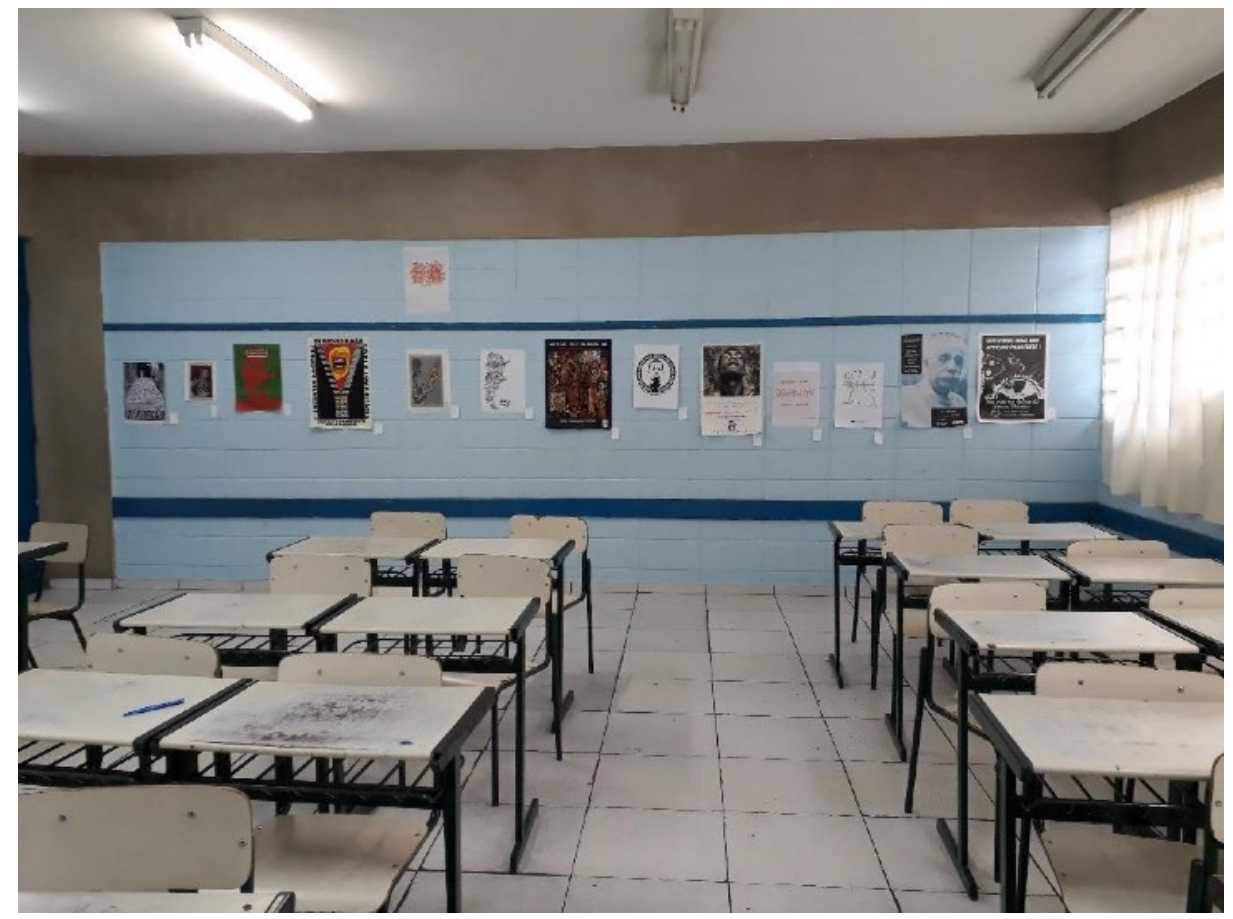

Fotografia de autoria da autora.

Figura 2. Cartazes produzidos durante a greve por professoras/es e estudantes usados como referência em aula sobre comunicação visual. (março/2018).

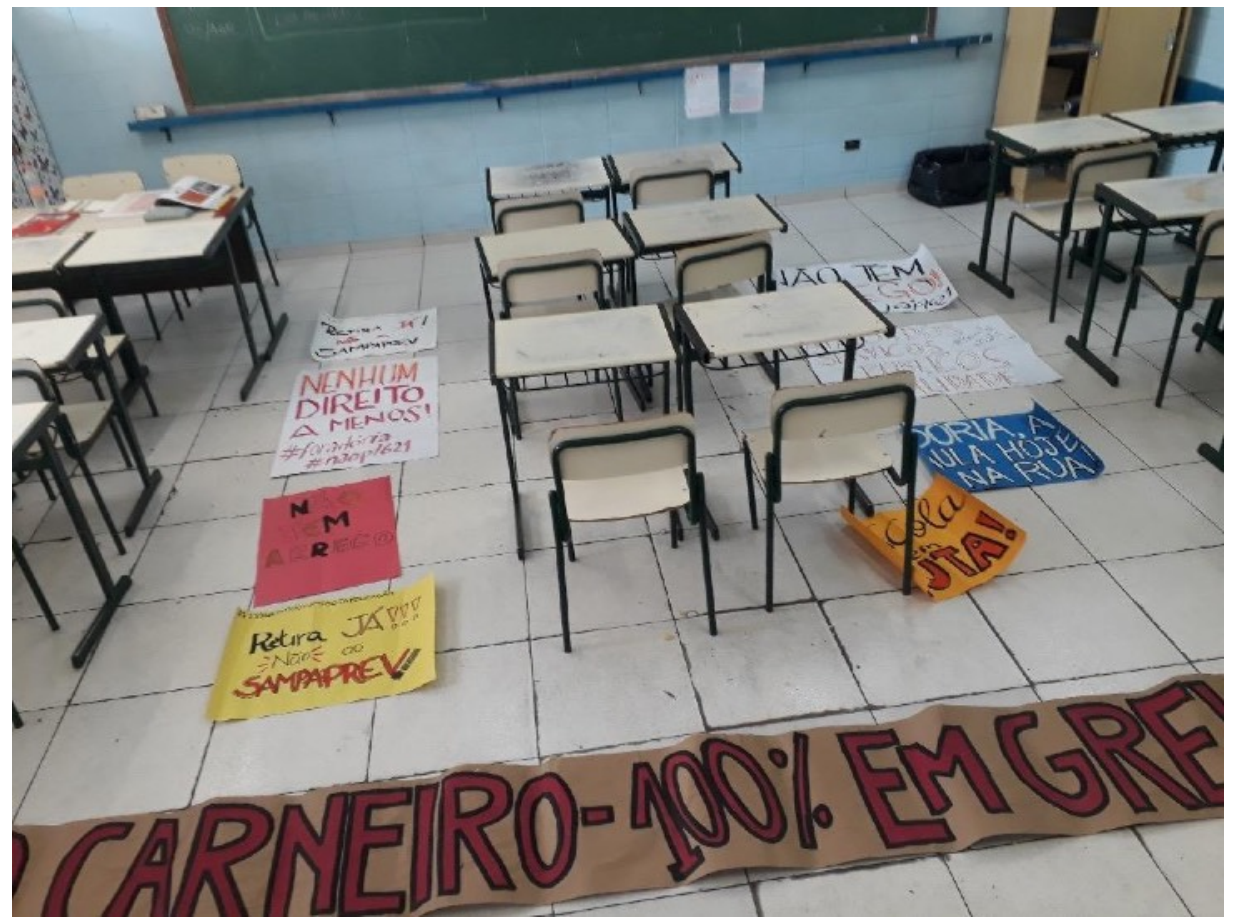

Foto da autora. 
Uma das referências utilizadas foi um cartaz do coletivo argentino Taller Popular de Serigrafia (fig. 3), grupo formado em 2002 por ocasião das assembleias organizadas durante as revoltas populares na Argentina em decorrência da crise econômica em 2001. Desde então, o coletivo entende que a imagem pode ser um suporte material para os problemas nos quais querem intervir e trabalha produzindo camisetas e cartazes no contexto das lutas sociais, movimentos de protestos e contra a repressão. Desse coletivo, o cartaz que escolhi levar para a sala de aula traz os dizeres em espanhol "diferentes desejos / direitos iguais" e seu sentido se completa com um desenho de beijos entre casais hétero e homoafetivos. Não por acaso, esse cartaz em especial chamou a atenção de um grupo de meninas que o fotografaram em seus celulares e depois escolheram esse tema para os seus próprios cartazes. A imagem como suporte para intervir em uma questão que sempre existiu e esteve invisível no cotidiano visual da escola. Ver, ser vista.

Figura 3

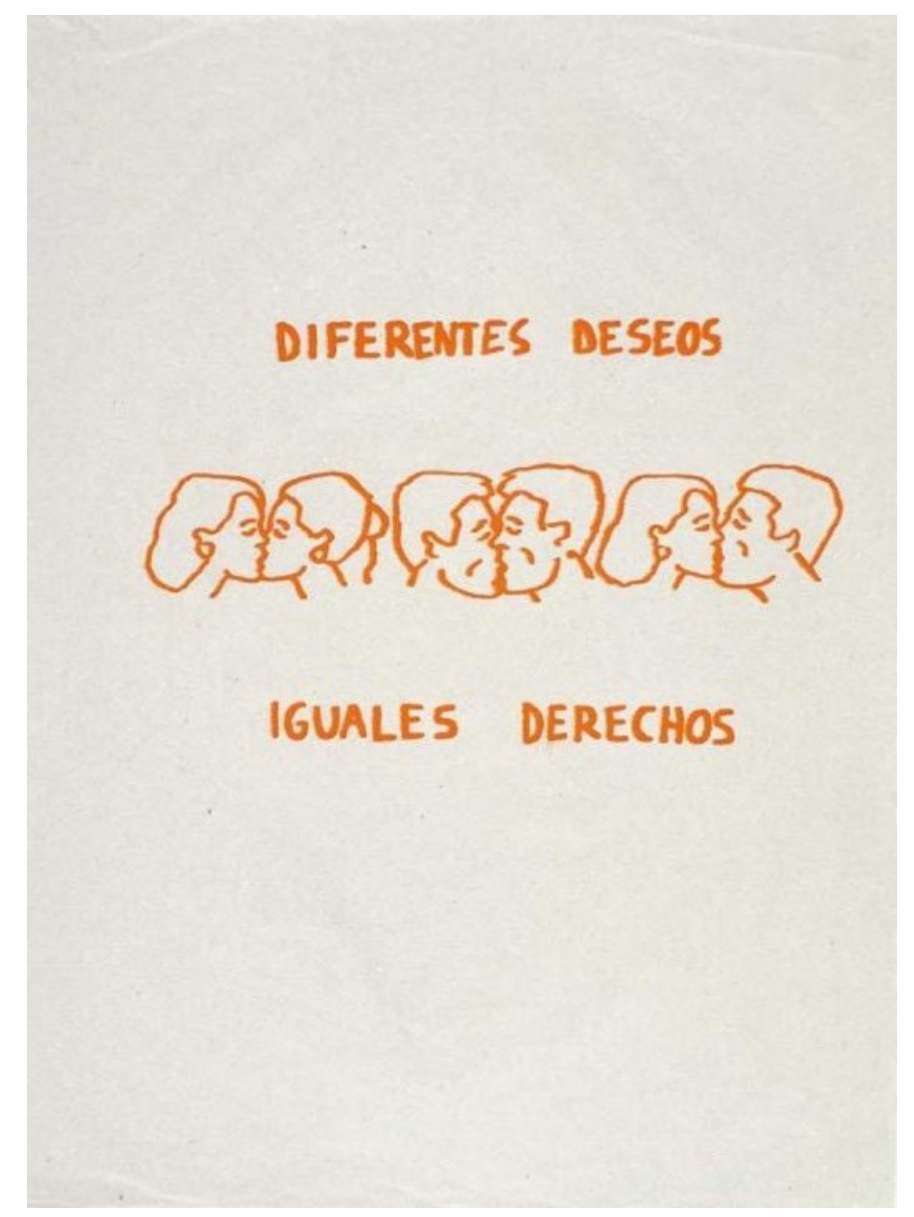


O segundo cartaz (fig.4) que destaco aqui foi tirado do livro da campanha gráfica \#vivasnosqueremos, que reúne um compilado de cartazes produzidos por diversas mulheres também na Argentina, inspiradas pela coletiva MuGre (Mujeres Grabando Resistência), no México, que decidiu utilizar a gravura para criar imagens com mensagens claras como veículo para denunciar, enunciar e visibilizar os diferentes modos de violência exercida contra as mulheres (2017, p. 6). Os dizeres "um dia não terás medo de andar pela rua nem terás medo de morrer pelo teu machismo" acompanham a perspectiva de uma rua escura e, ao final dessa rua, uma mulher caminha sozinha. Esse cartaz também despertou o interesse de algumas estudantes e permaneceu boa parte do ano na sala de artes, sempre sendo alvo de curiosidade, questionamento e observação.

Figura 4. Cartaz da Campanha Gráfica \#vivasnosqueremos,

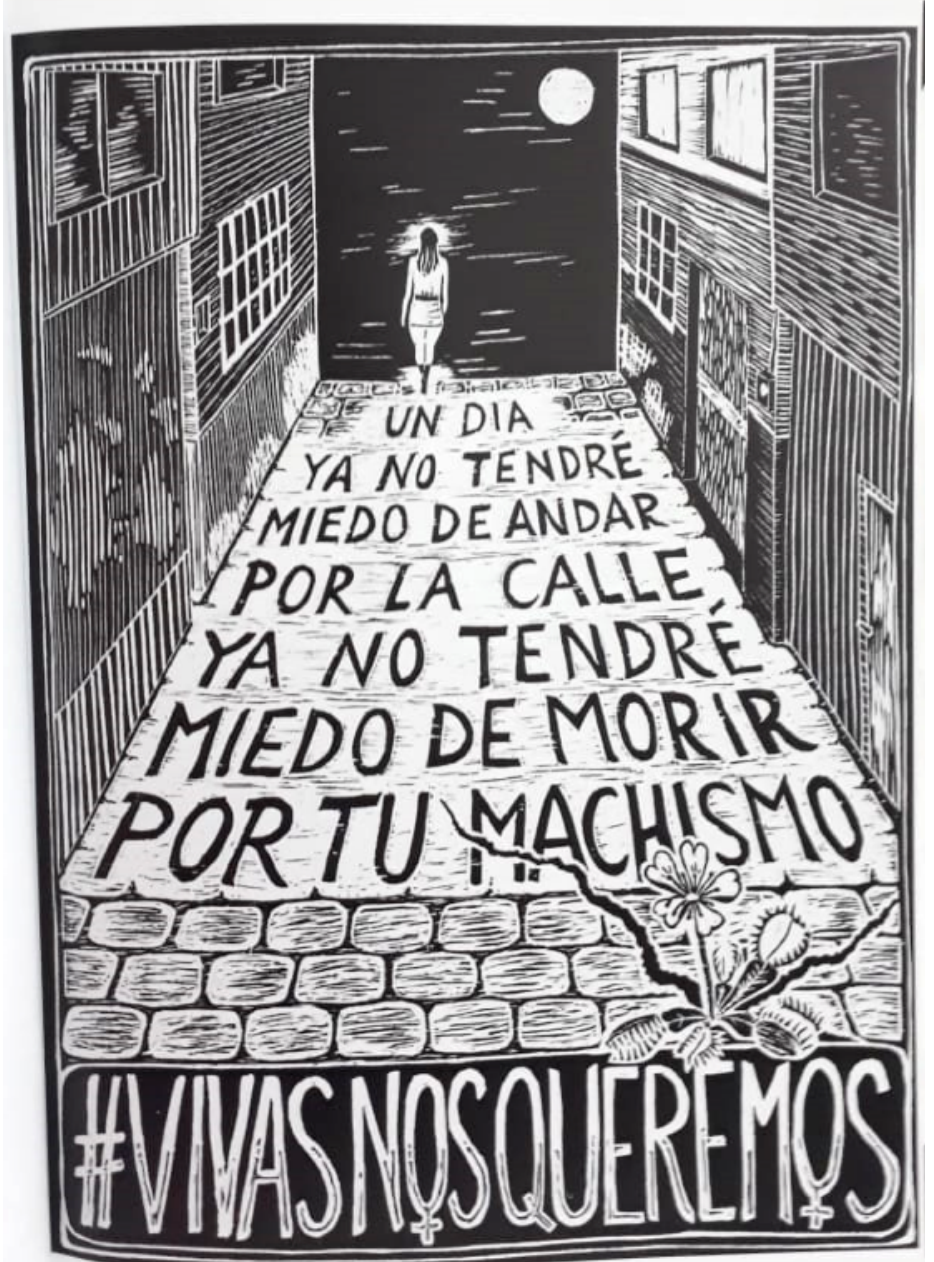

Fonte: Muchas Nueces,: El Colectivo : Editorial Chirimbote. Argentina, 2017. 
Essas foram algumas das referências de cartazes que me levaram a refletir sobre a influência que a natureza das imagens vistas pelas estudantes pode ter sobre o que elas produzem em sala de aula, observando o teor político e contestador presente em muitos dos cartazes que elas criaram em seguida- Ainda que, a princípio, eu tenha saído um pouco frustrada com relação à minha expectativa sobre as aulas em que propus a leitura e análise dos cartazes (fig.1), acredito que o resultado teria sido diferente se as referências apresentadas focassem mais em conteúdo publicitário ou em frases de efeito, por exemplo.

É raro encontrar qualquer coisa que demova estudantes dos $9^{\circ} \mathrm{S}$ anos de sua apatia rotineira e com os cartazes não foi diferente: durante a aula, a maioria sequer se levantou do seu lugar para olhar de perto os cartazes que deixei expostos na sala e, quando chegou o momento de criarem os seus, frases prontas e de efeito dessas que circulam pela internet junto com imagens mais ou menos aleatórias -, corações, flores, estrelas e, ao contrário do que orientei, nenhum planejamento foram as saídas mais fáceis e imediatas para aqueles e aquelas que ainda se dispuseram a criar algo.

Compreendo, entretanto, que a escolha por temas de cunho político por parte de algumas e alguns estudantes não diz respeito exclusivamente aos cartazes vistos rapidamente em uma aula de 45 minutos. Essa escola de onde falo possui alguns projetos e um (pequeno) grupo de professoras e professores que tensiona, na medida do possível, algumas discussões acerca das minorias políticas e dos direitos humanos. Não por acaso, parte dessas e desses estudantes cujos cartazes refletiam tais discussões é também engajada nesses projetos da escola e mais participativa nessas aulas.

Sem dúvida, o repertório visual das estudantes não se restringe ao ambiente escolar, mas se entendermos que escola ainda pode ser um espaço de criação e negociação de sentidos e significados, as imagens ofertadas por ela poderiam exercer um papel importante no processo de ampliar as possibilidades de leitura, interpretação e construção de significados das coisas do mundo. De acordo com Tourinho, a cultura visual enfatiza a "utilização social, afetiva e político-ideológica 
das imagens e as práticas culturais e educativas que emergem do uso dessas imagens" (2011, p. 12). Assim, não deveríamos tratá-las como fixas e prontas para serem consumidas apenas, mas assumirmos também nossa responsabilidade enquanto sujeitos produtores de imagens e constantemente ativos na construção de seus significados, não só ao interpretá-las, mas também pelo uso que fazemos delas.

Nesse sentido, Raimundo Martins argumenta que os lugares sociais por onde cada indivíduo circula influenciam na interpretação que fazem de objetos e imagens (2011, p. 18). Nas suas palavras,

O território visual onde as pessoas estão situadas - moram, frequentam etc. -, ou seja, o contexto das esferas das suas relações com o mundo as coloca num processo de construção de sentidos e significados, de práticas de interpretação. As práticas artísticas/ imagéticas devem ser tratadas prioritariamente como espaços de aprendizagem, espaços de experimentação de professores e alunos como atores do processo educacional no qual esses fazeres revelam seu caráter social e, sobretudo, seu sentido ético e profissional. Nesses processos de aprendizagem, imagens e objetos de arte representam estímulos para a realização de propostas de visualidades territoriais, cujo reconhecimento depende de exposição, de circulação e, também, de experiências de visualização que levem em conta as diferentes interpretações contextuais e ideológicas que as formam e informam. (MARTINS, 2011, p. 18)

Nesses espaços de aprendizagem, quanto mais diversos forem os estímulos visuais, mais diversas serão as experimentações e a natureza das aprendizagens que eles proporcionarão. Sobre essa prática de produção de significados, Tourinho acrescenta que ela "depende do ponto de vista do observador/espectador em termos de classe, gênero, etnia, crença, informação, faixa etária, formas de lazer e demais experiências socioculturais" (2011, p. 12), então, se não há um esforço nesses territórios visuais em afirmar ou mesmo apresentar discursos destoantes daqueles normatizados, as práticas artísticas e educativas continuarão a reforçar a norma e, uma vez que muitas e muitos estudantes não se encaixam ou identificam com essa norma, a resposta poderá, na maioria das vezes, ser pasteurizada ou abafar e silenciar aqueles pontos de vista e lugares sociais destoantes.

Assim, levar ao ambiente escolar referências visuais e discursivas diferentes das habituais pode servir não apenas como um estímulo, mas também como uma 
"autorização" para sair da linha, já que esse mesmo ambiente todos os dias ensina ser necessária algum tipo de autorização para seguir ou desviar dos caminhos previamente determinados.

Figura 5. Cartaz produzido por estudantes do $9^{\circ}$ ano. (abril/2018).

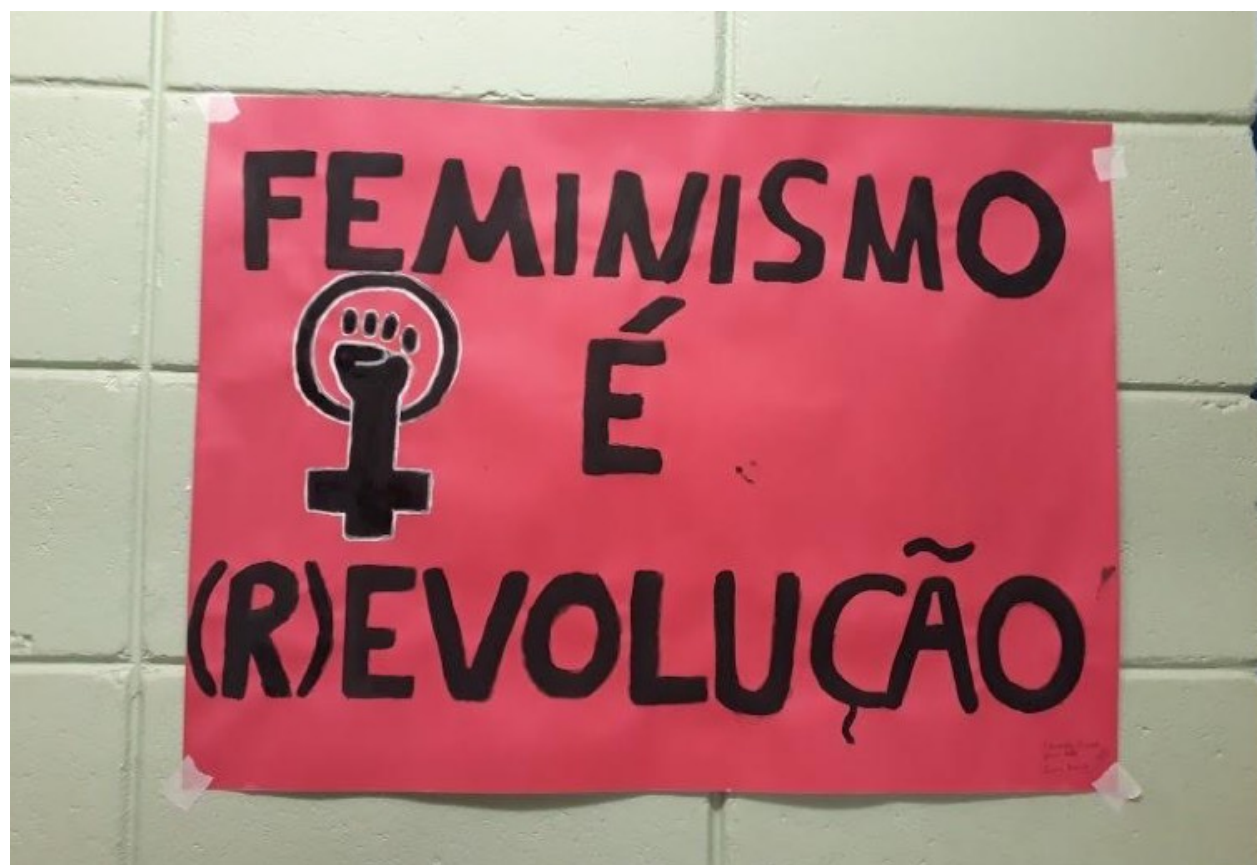

Foto da autora.

Figura 6. Cartaz produzido por estudantes do $9^{\circ}$ ano. (abril/2018).

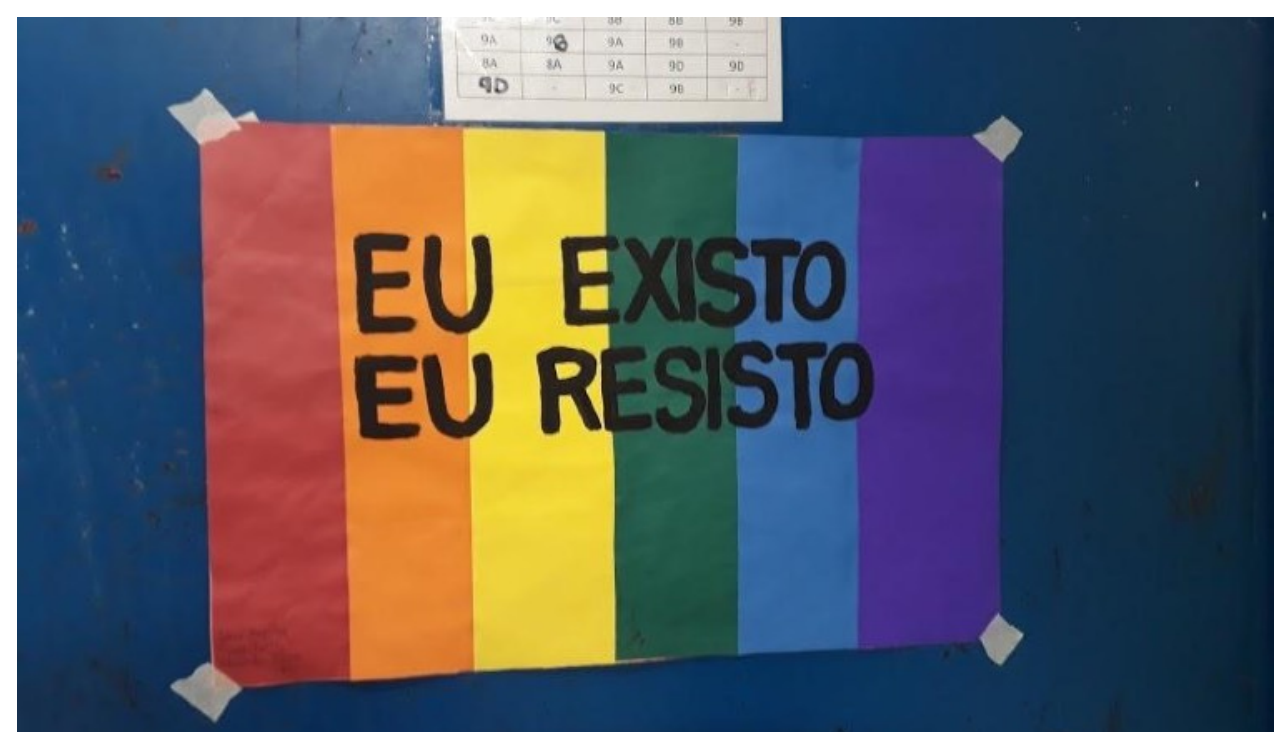

Foto da autora. 
As reações aos trabalhos das e dos estudantes, uma vez colocados pela escola nos lugares escolhidos por elas e eles, foram diversas: muitas foram positivas, como alguns/as professoras/es e estudantes que manifestaram apreço por ver a escola mais colorida, com suas ideias espalhadas por ela; as reações negativas foram, em sua maioria, veladas: chegaram até mim, primeiro, através de um "telefone sem fio" e de olhares de reprovação. Os evidentes incômodos gerados pela visibilidade às discussões como homofobia e machismo não foram expostos nem debatidos de forma política nem pedagógica pelo corpo docente e gestão da escola, como, do meu ponto de vista, seria coerente em uma instituição que, por princípio, deveria ser democrática e respeitar a pluralidade de ideias. Ao contrário, quando esses incômodos são ignorados ou tratados de maneira pessoal, até onde pude perceber em nada somam ao debate sobre homofobia e machismo na escola, tampouco contribuem para a construção da liberdade e espaços de voz que as/os estudantes possuem ali, além de colocar em dúvida esse mesmo espaço de voz e liberdade que o corpo docente deveria ter.

Aconteceu, então, que estudantes de outras turmas que não participaram do processo de criação dos cartazes se sentiram estimuladas a colocar suas ideias no papel e nas paredes da escola. Tais estudantes eram meninas do $7^{\circ}$ ano, ávidas por falar sobre machismo e, principalmente, sobre assédio, e de expor algumas opressões que vinham percebendo e com as quais não concordavam - daí a necessidade de torná-las visíveis. Incentivei que assim o fizessem; emprestei material para isso e, quando elas vieram me entregar os primeiros cartazes, como se fosse um trabalho que valia nota, emprestei também a fita adesiva e as estimulei a colarem os próximos sem precisarem da minha autorização, uma vez que aquilo era iniciativa delas e, a meu ver, a escola é (ou deveria ser) um espaço delas e para elas, estudantes.

Demorou mais alguns meses até que eu fosse chamada na sala da coordenação, em decorrência da reclamação de algumas professoras especificamente sobre dois cartazes, um feito por uma estudante do $9^{\circ}$ ano no contexto da minha aula e outro feito por iniciativa de uma estudante do $7^{\circ}$ ano. Os dois cartazes tinham em comum a imagem de um dedo do meio: no primeiro, o dedo aparecia dentro do símbolo do feminismo (fig. 7) e acompanhava uma mensagem 
sobre a liberdade de se vestir como quiser; o segundo, do qual infelizmente não tive tempo para fazer nenhum registro fotográfico por logo ter sido retirado, tinha muita informação visual e, por isso, era de difícil leitura e mal dava pra ver o tal dedo do meio, acompanhado de um "foda-se seu machismo" e dizeres sobre assédio e liberdade das mulheres.

Figura 7. Cartaz produzido por estudantes do $9^{\circ}$ ano. (abril/2018).

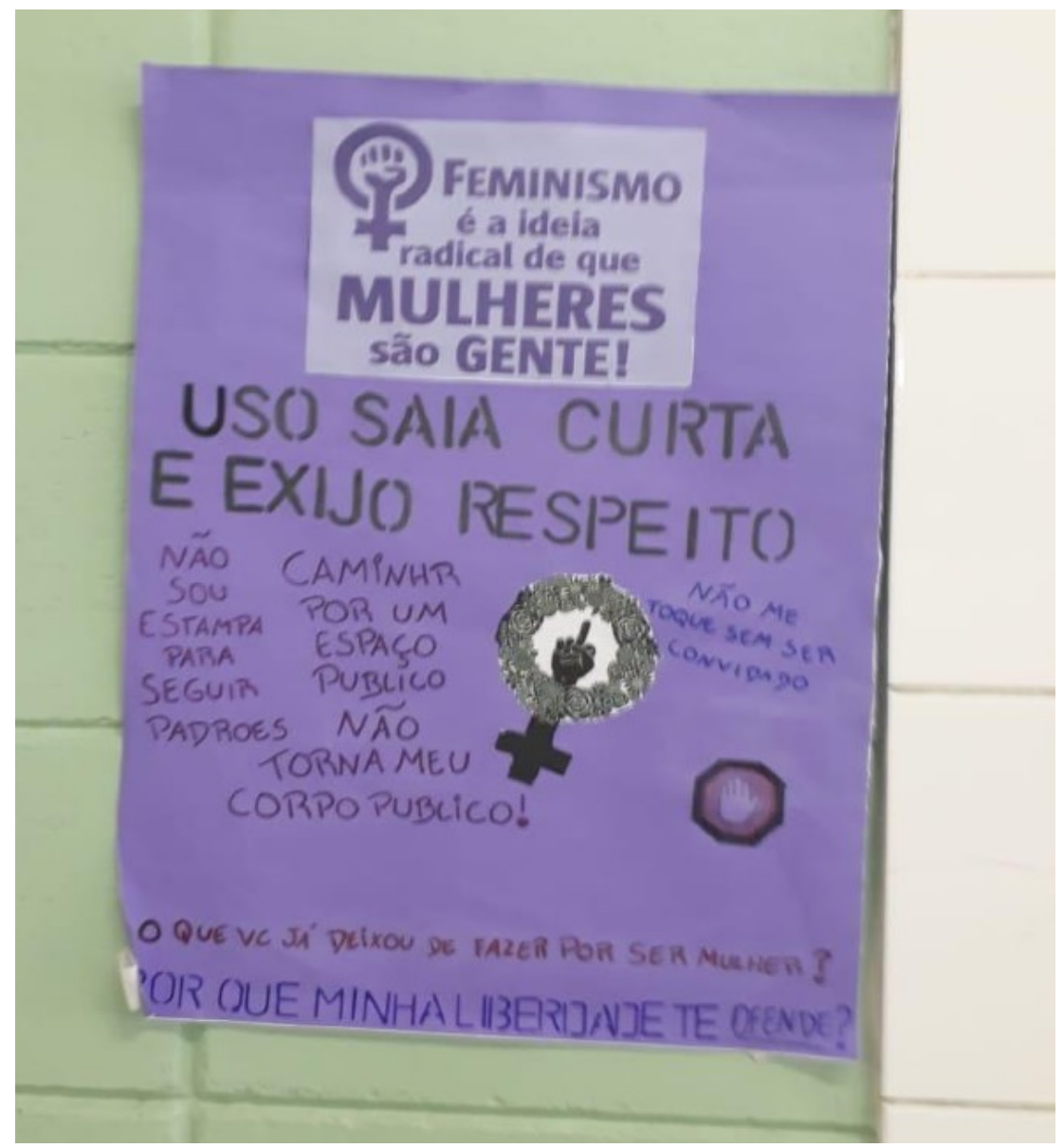

Foto da autora.

O argumento a mim apresentado foi de que esse símbolo seria impróprio para o ambiente escolar, principalmente para as crianças do $1^{\circ}$ ao $5^{\circ}$ ano, diante das quais as professoras ainda tentavam repreender tais gestos e comportamentos. Têlos expostos na escola seria, no mínimo, contraditório ao trabalho delas, além de incentivar atitudes consideradas indesejadas. De fato, durante a elaboração dos 
cartazes com os $9^{\circ} \mathrm{S}$ anos, conversei com estudantes pensando em como evitar palavrões e possíveis ofensas, considerando justamente que, pela diversidade de interlocutores que a escola tem em termos de faixa etária e posicionamento político, a mensagem estaria mais acessível e poderia ser recebida de forma mais ampla se comunicasse alguma ideia, ao invés de apenas repelir outra. Entendo que negar e repelir também são formas importantes de se comunicar uma ideia e, por isso, me perguntei muitas vezes se encontrar com as/os estudantes formas alternativas de dizer "foda-se" e se fazer entender não seria também uma forma de censura; ou se, por outro lado, a liberdade de dizer o que se pensa realmente pressupõe o cuidado com a forma com que se diz e para quem se diz.

Entendi que a reclamação se dirigia ao dedo do meio, mas que o incômodo não se limitava a ele. Falar sobre assédio na escola é incômodo. Falar sobre homossexualidade na escola, mais ainda. Principalmente nesse momento político, em que o conservadorismo da "tradicional família brasileira", que não por acaso não corresponde às famílias de quase nenhum/a daqueles/as estudantes da periferia da zona norte da cidade - e, aposto, das outras periferias também -, reivindica o controle sobre a educação e a política.

Quando uma imagem de um dedo do meio é censurada em um ambiente repleto de imagens pouco diversas em termos formais, estéticos e discursivos, somos levadas a prestar atenção na quantidade de informações reforçadas silenciosamente, dia após dia, através da visualidade. Não é difícil compreender os motivos pelos quais uma imagem de um dedo do meio pode desagradar e contrariar muitas pessoas mas, não estaria implícito nesse incômodo o pressuposto da naturalização das outras imagens aceitas e bem vistas por serem agradáveis, "fofas", coloridas e doces (e, portanto, entendidas como próprias para um ambiente de convívio infanto-juvenil)?

Ouvi ainda que nossos alunos não têm autonomia para colar cartazes pela escola e que, mesmo os cartazes que não foram feitos em aula, eles precisam passar pelo nosso crivo; precisam do nosso aval, da nossa autorização e curadoria. Desde então, venho me perguntando como se constrói autonomia com sujeitos que não têm autorização para existir sem a mediação de uma autoridade. 


\section{PARA ONDE APONTA O DEDO DO MEIO?}

Ao reclamarem sobre o assédio que estavam sofrendo de colegas, algumas meninas ouviram da gestão da escola o mesmo que ouvem de seus familiares: que elas deveriam sair de perto ou ignorar. Ou, ainda, que não deveriam "dar ousadia". Essas palavras, no entanto, aparentemente soam menos ofensivas ou violentas que a imagem de um dedo do meio em resposta ao assédio sofrido. Aliás, a julgar pelas providências tomadas, a imagem do dedo do meio parece ser mais grave do que o próprio assédio.

Não é possível passar despercebida a forma como as relações se constroem de forma violenta no cotidiano do espaço escolar, mediadas por uma arquitetura violenta que, como já dito, operam numa lógica proibitiva e restritiva. Nesse cenário, são constantes as agressões físicas e verbais entre estudantes e, não raro, entre estudantes e professoras e professores. Palavrões, insultos de toda ordem, xingamentos e gestos ofensivos fazem parte do vocabulário corriqueiro das e dos estudantes. A imagem de um dedo do meio, um dos gestos mais presentes nessas relações escolares, poderia incitar mais violência? Evitá-la poderia coibir tal comportamento?

Não se trata de naturalizar as agressões. Mas, talvez, também não se trate de uniformizar as referências visuais do ambiente escolar com imagens pautadas em uma ideia fixa de infância, em sua maioria conformada por um discurso não apenas sexista ("meninos usam azul, meninas usam rosa"), mas colonizador (branco e eurocêntrico) e voltado para a lógica do consumo e, ao mesmo tempo, ignorar a linguagem e vocabulário verbal, visual e gestual impregnados de violências e insultos (mas não apenas disso) que faz parte das relações dessas e desses estudantes dentro e fora da escola.

Incorporar como parte do processo educativo as dúvidas, medos e desejos do jovem, convertido em sujeito com biografia, em contraponto a "coisificar" meninos e meninas através de um currículo compartimentado e disciplinar pode ser, segundo Hernández (2005, p. 29), uma ponte possível de ser estabelecida a partir da cultura visual por educadores que 
não esquecem que quando olhamos (e produzimos) as manifestações que fazem parte da cultura visual não estamos olhando apenas para o mundo, mas para as pessoas e suas representações e as consequências que elas têm sobre sua posição social, gênero, classe, raça, sexo etc. (HERNÁNDEZ, 2005, p. 29. Tradução Nossa) ${ }^{1}$

É por esse viés que podemos considerar se as diferenças de classe e etária entre as professoras que se incomodaram com a imagem do dedo do meio e as estudantes que a colocaram em um cartaz com um objetivo específico não seria um primeiro indicativo do que essa imagem representa e como afeta esses diferentes lugares sociais. Outro fator relevante seria lembrar que a gestão da escola, portavoz do incômodo que essa imagem gerou, em outras ocasiões se omitiu diante de situações de assédio apresentadas pelas estudantes.

Ainda em diálogo com Hernández (2011, p. 77), como ponto para pensar as imagens e as relações que estabelecemos com elas, podemos retomar a pergunta sobre que olhares culturais essas imagens presentes no ambiente escolar propiciam e que experiência de subjetividade mediam: ao invés de ser vista como meramente violenta, a imagem do dedo do meio nos cartazes em questão poderia também ser entendida como uma reação à opressão estrutural machista, vivida cotidianamente por meninas e mulheres. Essa imagem tanto poderia influenciar negativamente as crianças e adolescentes, se considerada descolada do seu contexto, quanto poderia instigá-las a pensar e/ou levá-las a se identificar com o teor e motivação dos cartazes.

A questão é mais complexa do que apenas escolher um lado, escolher uma dessas leituras possíveis, mas evidencia um posicionamento sobre um tipo de experiência de subjetividade que se deseja coibir, aquele violento, agressivo e desafiador, representado pela imagem do dedo no meio, e outro que se invisibiliza e silencia, através da omissão e apagamento de suas marcas da parede, que é aquele questionador e também desafiador, que contesta estruturas opressoras. Se a escola assume esse lugar de combater - ou não incentivar - comportamentos agressivos

\footnotetext{
1 Cf: "no olvidan que cuando miramos (y producimos) las manifestaciones que forman parte de la cultura visual no estamos sólo mirando al mundo, sino a las personas y sus representaciones y las consecuencias que tienen sobre sus posicionalidades sociales, de género, clase, raza, sexo, etc"
} 
excluindo a imagem de um dedo do meio do seu campo visual, o que poderia fazer para combater o assédio além de responsabilizar as meninas e silenciar mecanismos que elas encontraram para questioná-lo, uma vez que, nesse caso, não se posicionar já é um posicionamento?

Há outro ponto importante a ser observado: os cartazes com conteúdo mais objetivamente político e contestatório foram feitos pelas meninas, enquanto as poucas mensagens políticas feitas por meninos, em sua maioria, tinham um tom mais genérico e não se dirigiam a nenhuma pauta específica, como mensagens contra desigualdade ou justiça social, por exemplo. Isso me leva a considerar a possibilidade de que, além da socialização das meninas ensinar que sejam mais caprichosas, obedientes, boas alunas e, consequentemente, que levem as propostas das aulas mais a sério, elas podem ter mais coisas a dizer e/ou menos espaço para isso. Desse ponto de vista, a iniciativa das estudantes de cutucar a ferida aberta do machismo com o dedo do meio demonstra a necessidade de debater esse tema na escola e o despreparo da escola para fazê-lo. A imagem, associada por elas não apenas ao "foda-se seu machismo" do cartaz, mas também à ideia de liberdade para as mulheres, ainda que de uma forma dispersa, criou alguma fissura no cotidiano visual escolar, dominado majoritariamente por imagens decorativas ou didáticas que não problematizam nem colocam em questão as questões das/dos estudantes.

\section{CONSIDERAÇÕES FINAIS}

Ao refletir sobre paradigmas do que seria uma educação anarquista para os dias de hoje, Silvio Gallo (1995) aponta que a ideologia, através da escola, apresenta aos indivíduos a realidade da máquina social de produção como sendo a realidade, inserindo-os dentro dela de modo que não haja oposição possível. O autor também argumenta que "se necessariamente desempenha uma ação ideológica, a escola também pode desempenhar uma ação contra-ideológica que consistiria no desenvolvimento de um processo de subjetivação autônomo" (GALLO, 1995, p. 66), capaz, portanto, de levar a formação de indivíduos livres. Segundo ele: 
Uma educação contra-ideológica, autônoma e libertária, precisaria começar por destruir o panorama enquanto referencial balizador de subjetivação; por aí já vemos que a noção de escola libertária como uma escola na qual as crianças são deixadas à mercê de sua autoorganização não passaria, realmente, de um tacanho liberalismo, pois na ausência de referenciais colocados diretamente através da relação professor/aluno o grande referencial, em última instância, seria o da própria máquina social de produção, permanecendo como o horizonte para os processos de subjetivação. Mas de onde partiria a ação desta escola libertária? (GALLO, 1995, p. 66)

Se tomamos as imagens presentes no ambiente escolar como referências visuais que, em sua maioria, não têm um posicionamento abertamente contraideológico no sentido usado por Silvio Gallo, podemos inferir que o que essas imagens fazem, de forma implícita, é reforçar o que já está posto, o panorama da máquina social de produção.

Podemos considerar que ser contra-ideológico não diz respeito apenas a realizar um debate verbal e teórico sobre o panorama social, mas também a considerar o que precisa ser repensado em termos de práticas, assim como de visualidade. Ana Mae Barbosa (2011) entende a cultura visual, no ensinoaprendizagem da arte, como geneticamente contra-hegemônica e destaca uma de suas linhas, à qual se refere como contracultura visual. Segundo Barbosa, a contracultura visual critica o discurso verbal sobre a visualidade; acrescentando que:

(...) considera a cultura visual praticada até agora no ensino da arte como uma apologia da publicidade e da indústria cultural; clama por uma crítica mais contundente ao capitalismo que questione a submissão da cultura ao sistema político (...). A contracultura visual, antes de tudo, procura exercer a crítica visualmente. Outros discursos são entrelaçados, mas a contravisualidade é imprescindível; é a crítica feita visualmente e não apenas verbalmente. (BARBOSA, 2011, p. 294)

Propor as intervenções na escola foi uma forma de tentar ocupar seus espaços com a voz e a presença dos e das estudantes visualmente; de contrapor as imagens familiares ao ambiente escolar com outros discursos visuais e verbais não necessariamente bonitos ou agradáveis, mas mais diversos e não exclusivamente decorativos ou recreativos. Percebi que dentro da escola pública, assim como acontece fora dela, ocupar é também disputar espaços e narrativas, já que são 
diversos os obstáculos que assumem formas institucionais e se apresentam através da arquitetura, do corpo gestor e docente, da ordem insípida e homogeneizante da limpeza, da contenção dos ruídos visuais e sonoros e da internalização de todas as violências cotidianas que reafirmam o silêncio como norma.

Confrontar e questionar essa neutralidade discursiva das imagens no ambiente escolar de maneira construtiva significa não apenas reinventar outros modos de existir nesses espaços e resistir as suas imposições predeterminadas, mas de deslocar o pensamento hegemônico, a fim de se fazer ouvir e ecoar outras vozes, considerando-as em uma perspectiva pedagógica, teórica e prática. Em outras palavras, seria buscar uma pluralidade de vozes na sala de aula e no ambiente escolar como um todo e sustentá-la através de práticas pedagógicas menos excludentes e mais sensíveis às diferentes trajetórias e pontos de vista, de modo a criar espaços de compartilhamento, e não de reforçar estruturas de poder já existentes. Isso implica também em explorar referenciais teóricos, leituras e saberes mais diversos que, nas palavras de Djamila Ribeiro, busquem "desestabilizar e transcender a autorização discursiva branca, masculina cis e heteronormativa" (RIBEIRO, 2017, p. 28).

\section{REFERÊNCIAS}

ANÓNIMO. Vivas nos queremos. - $1^{\mathrm{a}}$ ed. llustrada. - Ciudad Autónoma de Buenos Aires : Muchas Nueces : El Colectivo : Editorial Chirimbote, 2017.

BARBOSA, Ana Mae. Tópicos Utópicos. Belo Horizonte: C/ Arte,1998. p. $293-301$.

A cultura visual antes da cultura visual. Educação, v. 34, n.3, Porto Alegre, 2011.

FREIRE, Paulo, A importância do ato de ler: em três artigos que se completam. São Paulo: Autores Associados: Cortez, 1989.

GALEANO, Eduardo. O livro dos, tradução de Eric Nepomuceno. - 9. ed. Porto Alegre: L\&PM, 2002.

GALLO, Silvio. Educação anarquista: um paradigma para hoje. Piracicaba: Unimep, 1995.

HERNÁNDEZ, Fernando. A cultura visual como convite à deslocalização do olhar e o reposicionamento do sujeito. In: MARTINS, Raimundo; TOURINHO, Irene (org.). Educação da cultura visual: conceitos e contextos. Santa Maria: Ed. da UFSM, 2011. 
Da Alfabetização Visual ao Alfabetismo da Cultura Visual. In MARTINS, Raimundo; TOURINHO, Irene. (Orgs.) Educação na cultura visual: narrativas de ensino e pesquisa. Santa Maria RS: ED. Da UFSM, 2009.

Fernando. De que hablamos cuando hablamos de cultura visual? Educação e Realidade, 30(2), 2005. p. $9-34$.

MARTINS, Raimundo. Imagem, identidade e escola. In: MENDONÇA, R. (coord.). TV Escola / Salto para o futuro: Cultura Visual e Escola. Ano XXI, Boletim 09, ago. 2011, pág. 09-14. Disponível em: https://docente.ifrn.edu.br/isabeldantas/festa-e-ludicidade/arteeducacao/imagem-identidade-e-escola.-martins-raimundo. Acesso em: 30 jun. 2019.

RIBEIRO, Djamila. O que é lugar de fala? Belo Horizonte: Letramento; Justificando, 2017.

TAVIN, Kevin. Contextualizando visualidade no cotidiano: problemas e possibilidade do ensino da cultura visual. In MARTINS, Raimundo; TOURINHO, Irene. (Orgs.) Educação na cultura visual: narrativas de ensino e pesquisa. Santa Maria RS: ED. Da UFSM, 2009.

TOURINHO, I. As experiências do ver e ser visto na contemporaneidade: por que a escola deve lidar com isso? In: MENDONÇA, R. (coord.). TV Escola / Salto para o futuro: Cultura Visual e Escola. Ano XXI, Boletim 09, ago. 2011, pág. 09-14. Disponível em: https:// docente.ifrn.edu.br/isabeldantas/festa-e-ludicidade/arte-educacao/imagem-identidade-eescola.-martins-raimundo. Acesso em: 30 jun. 2019.

Irene. Educação estética, imagens e discursos: cruzamentos nos caminhos da prática escolar. In MARTINS, Raimundo; TOURINHO, Irene. (Orgs.) Educação na cultura visual: narrativas de ensino e pesquisa. Santa Maria RS: ED. Da UFSM, 2009.

\section{Sites visitados}

Bienal Internacional de São Paulo, Taller Popular de Serigrafia. Disponível em: <https:// entretenimento.uol.com.br/27bienal/artistas/taller_popular_de_serigrafia.jhtm> Acesso em: 12 jul. 2019

Taller Popular de Serigrafia. Disponível em: <http://tallerpopulardeserigrafia.blogspot.com/ > Acesso em: 12 jul. 2019

Astrocentro. Qual o significado da coruja em todas as culturas? Disponível em: <https:// www.astrocentro.com.br/blog/espiritual/qual-significado-da-coruja/>

Malba Diario, La serigrafia tiene un largo passado. Disponível em: <https://malba.org.ar/laserigrafia-tiene-un-largo-pasado/?v=diario > Acesso em: 14 jul.2019. 